\title{
A Tangled Web of Terms: The Overlap and Unique Contribution of Involvement, Engagement, and Integration to Understanding College Student Success
}

\author{
Lisa Wolf-Wendel Kelly Ward Jillian Kinzie
}

Established theories and constructs long associated with student success, including involvement, engagement, and integration, provide common language and a body of knowledge to inform understanding of the challenges currently facing higher education. This paper examines how the theories and terms have evolved, explores how the terms are currently used, and considers their legacy for understanding contemporary concerns about student development and success.

Increased attention from the federal government and education policy makers regarding low college graduation rates and concerns about the quality of undergraduate education have prompted greater public, practitioner, and scholarly discussion about student success in college (Kuh, Kinzie, Buckley, Bridges, \& Hayek, 2007; Kuh, Kinzie, Schuh, Whitt, \& Associates, 2005; State Higher Education Executive Officers, 2005; U.S. Department of Education, 2006). Accountability initiatives including the Voluntary System of Accountability (McPherson \& Shulenburger, 2006) and regional accreditation organizations have added intensity to conversations about student retention and the quality of student learning. Recent research reports published through the National Postsecondary Education Cooperative (NPEC) summarized the rich research base on student success (National Center for Education Statistics, n.d.). In addition to summarizing the research, the reports advocate for researchers and policymakers to be critical of the salience of tried and true theories of student retention and to pose questions about variations in how students participate in college and the extent to which current theories account for diverse learners.

Established theories and constructs long associated with student success, including involvement, engagement, and integration, provide common language and a body of knowledge to inform understanding of the challenges currently facing higher education in this era of increased scrutiny of student achievement. These theories have rich histories in research and have effectively guided educational practice for decades. However, it is important to take stock of how the theories and terms have evolved, to explore how the terms are currently used, and consider their legacy for understanding current concerns about student success. Lack of common definitions and understandings can lead to unclear communication and, worse, sloppy scholarship and ineffective practice.

This paper examines the concepts of involvement, engagement, and integration to determine how they are unique, how they overlap, and the extent to which the concepts are similar. These terms are in many ways distinct, yet we found in our research they are often used interchangeably; we find this habit

Lisa Wolf-Wendel is Professor of Educational Leadership and Policy Studies at the University of Kansas. Kelly Ward is Professor of Educational Leadership \& Counseling Psychology at Washington State University. Jillian Kinzie is Associate Director of the Center for Postsecondary Research and NSSE Institute at Indiana University. 
problematic given the rich histories of each concept. In particular, the paper addresses the following questions:

- What are the definitions of involvement, engagement, and integration?

- How did each of these concepts develop and evolve?

- How are the concepts distinct?

- To what extent do these concepts overlap?

- How are the concepts used in research and practice?

- What are the future implications for the use of these concepts?

- Why is it important to examine their use?

As faculty who teach about the impact of college on students, we repeatedly come across graduate students who do not understand the nuanced differences between involvement, integration, and engagement. Students often treat these important concepts as interchangeable. In the field, practitioners have a difficult time delineating where one concept ends and the next begins. Even researchers seem to have muddled the concepts, claiming to be studying one while adopting the traditional measurement and definition of another. As a result, these concepts get cloudy and are often interpreted as different in name only.

Why is it important to clarify the distinctions between the concepts of involvement, engagement, and integration? These concepts each add something unique and important to understanding student development and success that can be lost among those who cite them without fully understanding their definition and use. Such haphazard citations and usage can lead to further confusion about the concepts. Questions remain: Can students be involved but not engaged? Can they be academically and socially integrated but not involved? Are the policies and practices used to create an involving campus the same as those that will help students to be engaged and integrated? Such questions deserve further exploration. Clarification of the nuances of these concepts will add to the rigor and quality of research on college students and will offer clarity and explication of these three concepts for scholarship, policy and practice.

\section{METHODOLOGY}

The methodology for this study is grounded in a qualitative perspective in that it relies on the analysis and representation of words; yet, the project is not a typical qualitative study that relies solely on interviews. The literature related to engagement, involvement, and integration provided the initial impetus for the study and was used to frame the research questions and subsequent interview questions. The literature was also used as part of the data that we analyzed to help us untangle the concepts. Based on preliminary analysis of the literature we then identified interview participants based on their relationship to the concepts. We interviewed experts in the research on college students and college impact to understand more fully the concepts of integration, engagement, and involvement.

The expert (also called elite) interview is a specialized interview that is often relied upon in research related to political science when "elite" members of politics (e.g., state legislators) offer their perspective on issues germane to their area of expertise (Beamer, 2002; Dexter, 1970). The approach has been used to conduct educational policy research (Batteson \& Ball, 1995) as well but has not been as common in college student development research. The use of elite interviews for this study was warranted given the need to collect a very intentional set of information from researchers with particular frames of reference (Dexter, 1970). The content of the interviews was 
conceptual in nature in that the intent was to chart the development of the ideas related to integration, involvement, and engagement and to get elicit conceptual clarification. We relied on Kvale and Brinkmann's (2009) ideas related to the conceptual interview to "explore the meaning and the conceptual dimensions of central terms, as well as their positions and links within a conceptual network" (p. 151). We found this interview approach particularly appropriate given the purpose of the study to more fully understand the concepts and their application.

The interviews were conducted in two phases. Phase one included interviews with the individuals associated with the origin of the concepts (Alexander Astin, George Kuh, and Vince Tinto), and the second phase of the interviews included scholars who have applied the constructs in their research (Larry Braskamp, John Braxton, Shaun Harper, Sylvia Hurtado, Ernest Pascarella, Linda Sax, and Frances Stage). The viewpoints of those interviewed were essential to identify the unique contributions of each concept and its conceptual origin, and also to analyze how the concepts are applied in research and practice. All interviews were conducted over the telephone, recorded, and transcribed.

Each interview lasted approximately 45 to 60 minutes and followed a semistructured interview protocol. Interview questions included topics related to the origin of each theory, use of theory in research, use of theory in practice, overlaps of the concepts, examples of research and practice related to the theories, and future directions for research using these concepts. We were intentional to ask questions about the origin of the concepts in both phases of interviews because we wanted to be able to compare how the concepts were originated, how they were thought to be originated, and how they were ultimately used. We received human subject approval from the University of Kansas HSCL office and informed the interviewees of their right to participate or not. We also notified those interviewed that we would use their names in the paper.

The findings from the study are not based on an emergent analysis of the interview data; rather, we used the findings from the analysis of the literature and the interviews as a way to interrogate the concepts of integration, involvement, and engagement and to try to differentiate between the various theories, concepts, and ideas to determine their use and future directions in practice and research. The findings from the literature analysis provided the foundation and direction to guide the development and analysis of the interviews.

The data analysis was completed in stages. First, we reviewed relevant literature related to the three concepts to identify and chart the development of the ideas associated with each concept and to see how they related to one another. The results of the literature analysis helped identify questions for the first phase of expert interviews and also helped guide the analysis of the initial interviews. Next, the findings from the phase one interviews with the chief architects of each concept idea were used to triangulate what we found in the literature analysis to make sure we got the development of ideas "right." The data from the second phase of interviews, those researchers who apply the three concepts in their research, were analyzed to determine theoretical understanding (Kvale \& Brinkmann, 2009). We were not so much looking for individual understanding of how the researchers who apply the concepts make meaning of their own research, instead the analysis focused on how they use and make meaning of the concepts integration, involvement, and engagement.

To insure quality of the data and subsequent findings we triangulated that data from the interviews with what we found in the 
literature analysis. We also used investigator triangulation to add to the credibility of the study (Denzin, 1978). As a research team we were all involved in data collection, analysis, and interpretation to be sure that the findings of the study were credible. We also sent copies of our interpretations and findings to those we interviewed to assure attribution of ideas and clarity. Based on the feedback we edited and revised the paper and now turn to the presentation of the findings. Please note that throughout this paper when we refer to findings from the interview we provide last name only (e.g., Astin), yet when we refer to a particular scholarly work of a person interviewed we use a name, date entry (e.g., Astin, 1984).

\section{DEFINITIONS AND USAGE OF INVOLVEMENT, ENGAGEMENT, AND INTEGRATION}

Research on college students shows that the time and energy students devote to educationally purposeful activities is the single best predictor of their learning and personal development (Astin, 1993; Kuh et al., 2007; Pascarella \& Terenzini, 1991, 2005; Pace, 1984). What students do during college generally matters more to what they learn and whether they persist to graduation than who they are or even where they go to college. Pascarella and Terenzini (2005) reaffirmed the finding that the impact of college is determined primarily by individual student effort and involvement in the curricular and co-curricular offerings on a campus, though the total impact is also influenced by the campus itself. We operate under this premise as we turn to a fuller explanation of the terms involvement, engagement, and integration based on findings from the interview and literature analysis.

\section{Involvement}

Astin (1984) defined involvement as the amount of physical and psychological energy a student devotes to his/her academic experience. This involvement can be both academic and social, though much of the research using the theory of involvement has tended to focus on extracurricular involvement (Hernandez, Hogan, Hathaway, \& Lovell, 1999; Pascarella \& Terenzini, 1991, 2005). Astin (1984) hypothesized that the more involved the student is, the more successful he or she will be in college. He suggested that involvement is the investment of psychological and physical energy, which occurs along a continuum, with different students investing different amounts of energy. Astin (1984) added that involvement is both qualitative and quantitative, is related to learning, and can be encouraged by institutions to enhance educational effectiveness. The concept of involvement was first formally introduced in Astin's (1975) book, Preventing Students from Dropping Out, and was later presented more formally in his 1984 article. According to Astin, "The 1984 article, in its draft form, was used by the National Institute of Education Study Group that produced the widely cited report, Involvement in Learning [1984]. The Study Group embraced the involvement construct as the centerpiece of its national report on the state of higher education in the United States, which helped to popularize the concept."

The development of student involvement theory reveals some of its key themes, including its purpose and the focus on student behavior. Astin explained:

Involvement theory is an outgrowth of empirical research in an attempt to connect practice to outcomes. We needed to make sense of miscellaneous findings about student retention ... and how to draw 
findings together to develop an explanation of the different kinds of experiences that would lead to dropping out, or staying in college.

Astin's roots in psychology, particularly industrial psychology, led him to consider the relevance of the concept of "vigilance," or sustained attention to a task, to student retention. Astin concluded that vigilance and the concept of time on task were both insufficient to explain student retention as their applications were too narrow and did not account for the role of the environment. In contrast, Astin noted: "Involvement is a little wider. It covers a greater range of experience and behaviors." Astin found greater explanatory power in the combination of psychic energy, behavior, and the environment in relationship to retention.

For example, the residential experience clearly has a positive effect on student development and retention. But we wanted to know why-what was the mechanism for linking residential learning with retention? Involvement provided the theoretical link between practice and outcomes (residential living produces positive outcomes because it tends to enhance student involvement.

Involvement accounts for the time and energy that students spend but also acknowledges the contribution of the environment.

Involvement is typically utilized in research using the Input-Environment-Output (I-E-O) model proposed by Astin (1984). In I-E-O, individual characteristics are controlled for in order to isolate the effect of on-campus participation in various academic and social activities on various outcomes. According to Astin, "The advent of involvement theory led to the elaboration of the IEO model to include 'involvement' (also called 'intermediate outcomes') as an additional construct situated between Environment and Outcome (IEO).”
Though measured in multiple ways, much of the research that utilizes involvement theory measures time on task more than it does the expenditure of energy. The Cooperative Institutional Research Program (CIRP, 2008) student surveys based at the Higher Education Research Institute (HERI) at UCLA, ask students to indicate how often they participated in various educational activities. CIRP was founded more than 40 years ago to identify practices that lead to positive outcomes for students. The CIRP Freshman Survey asks entering students what they did in high school and the amount of time they spent on these activities, and the Your First College Year survey asks about time on task in the first year of college. These questions are often combined to determine the extent to which a student is involved both academically and socially. Activities such as working on campus, living on campus, engaging with peers, being a member of clubs, and socializing with faculty members are the types of involvement typically measured under this theory (Hernandez et al., 1999; Pascarella \& Terenzini, 2005). A variety of outcome measures, including satisfaction, grades, retention, and graduation have been linked to extracurricular involvement (Pascarella \& Terenzini, 1991, 2005). However, although both extracurricular and academic involvement are important, research shows that academic involvement (e.g., hours spent studying and doing homework, asking questions in class, studying with other students, completed homework assignments) has more significant effects than other type of involvement (Astin, 1977, 1993).

The institution is important to Astin's (1984) theory, in that the "effectiveness of any educational practice is directly related to the capacity of that policy or practice to increase involvement" (p. 298). However, the unit of analysis and focus is on the individual student, as he/she controls the extent of his/her own involvement. The CIRP surveys allow data to 
be aggregated at the institutional level to allow institutions to compare their students with various norm groups and alter institutional policies and practices based on findings. According to Astin, "CIRP conducts annual workshops for institutional representatives to assist them not only in interpreting their institutional reports, but also in conducting further longitudinal studies with their data."

One of the concerns raised by those interviewed for the study has to do with how the construct of involvement is measured. For example, some researchers look at membership in student organizations and focus on the numbers of clubs rather than the extent or intensity of involvement. As Astin noted, "A person can be completely absorbed in only one organization." He added:

Being in the French club might not mean much for the student. But certain kinds of organization memberships such as Greek-letter organizations, which typically demand considerable time and effort, are better representations of involvement . . . it is about putting time and energy into the thing.

Another issue raised by those in the field is that involvement tends to be used and applied to traditional age students rather than to the full spectrum of college students. Astin commented, "It happens that most of the empirical studies have focused on such [traditional age] students but that is a result of what data are available." Indeed, the CIRP data, on which much of the research on involvement is based, tends to be overrepresentative of traditional age students. Astin added, "Older students are probably affected by somewhat different forms of involvement, but I don't see involvement as not being equally relevant to students of all ages."

According to Astin, the advantages of involvement theory and the I-E-O model are that they are useful heuristic devices for thinking about what matters in the lives of students and what interventions we can create to make effective learning environments, and to specify what a student has to do to make the experience richer and more fulfilling.

Involvement theory is quite simply a "handy device" for researchers and practitioners. Astin also emphasized that the theory advances a fundamental truth: "learning experiences pay off in terms of what you invest in them."

In summary, how has the concept of involvement uniquely contributed to research and practice?

- It emphasizes academic, out of class settings and extracurricular activities.

- It focuses on the individual and the activities the individual does to become involved.

- Campuses have used the concept to develop programming and create offices to encourage student involvement to provide more opportunities for students to become involved in activities as part of a successful college experience.

- Involvement has been linked via research to almost every positive outcome of college.

\section{Engagement}

Originally influenced by quality of effort measures (Pace, 1980), the theory of involvement (Astin, 1985), and indicators of "good practice" in undergraduate education (Chickering \& Gamson, 1987), the concept of student engagement represents two key components. The first is the amount of time and effort students put into their studies and other activities that lead to the experiences and outcomes that constitute student success. The second is how institutions of higher education 
allocate their human and other resources and organize learning opportunities and services to encourage students to participate in and benefit from such activities (Kuh, 2001). The project that engendered the concept of engagement is called the National Survey of Student Engagement (NSSE) established by George Kuh (NSSE, 2009) The NSSE was originally developed under the guidance of a design team made up of scholars and practitioners including Alexander Astin, Gary Barnes, Arthur Chickering, Peter Ewell, John Gardner, Richard Light, and Ted Marchese, with input from C. Robert Pace.

According to Fran Stage, who looked up the etymology of the term engagement in the Oxford English Dictionary, engagement means "to bargain, make a contract, an agreement that parties enter into." Engagement is about two elements: what the student does and what the institution does. Engagement is about two parties who enter into an agreement about the educational experience. A challenge with the use of engagement in research related to student development and learning is that the term is used in higher education in multiple ways that are only loosely tied to the NSSE.. As indicated by Larry Braskamp, for example, engagement is used in multiple ways on college campuses, but many of these terms actually pre-date the work of the NSSE. For example, some people use the term as related to community service ("community engagement") or to suggest certain types of learning activities ("engaged learning"). This can lead to confusion about what engagement means. For the purposes of this paper, we focus on the use of the term engagement relative to the work of the NSSE.

High levels of student engagement are associated with a wide range of educational practices and conditions, including purposeful student-faculty contact, and active and collaborative learning. Engagement also is associated with institutional environments that are perceived by students as inclusive and affirming, and where expectations for performance are clearly communicated and set at reasonably high levels (Chickering \& Reisser, 1993; Kuh et al., 2005; Kuh, Schuh, Whitt \& Associates, 1991; National Center for Higher Education Management Systems, 1994; Pascarella \& Terenzini, 1991, 2005). These and other factors and conditions are related to student satisfaction, learning and development on a variety of dimensions, and also to persistence and educational attainment (Astin, 1984, 1985, 1993, 1999; Bruffee, 1993; McKeachie, Pintrich, Lin, \& Smith, 1986; Pascarella \& Terenzini, 1991, 2005; Pike, 1993). Participating in educationally purposeful activities directly influences the quality of students' learning and their overall educational experience. Therefore, high levels of student engagement are necessary for, and contribute to, collegiate success (Kuh et al., 2005, 2007).

The NSSE is an instrument specifically designed to assess the extent to which students are engaged in empirically derived, good educational practices and what they gain from their college experience (Kuh, 2001; NSSE, 2000). Although the NSSE does not assess student learning outcomes directly, the main content of the NSSE instrument, The College Student Report, represents student behaviors that are highly correlated with many desirable learning and personal development outcomes of college. The instrument asks students to report how they spend their time, the quality of their experience, and how they feel they have developed as a result of attending college. The items included in the NSSE instrument are derived from other student questionnaires including the College Student Experiences Questionnaire (CSEQ), the CIRP freshman and follow-up surveys, and student and alumni surveys administered by the University of North Carolina system. 
The NSSE reports institutional results on five benchmarks of effective educational practice: academic challenge, active and collaborative learning, student-faculty interaction, enriching educational experiences, and supportive campus environment. The construct of student engagement points to activities on the part of the individual student and the institution that are related to desired outcomes of college.

One conclusion to be drawn from our interview with Kuh is that student engagement was not developed as an extension of involvement but as an expression of the importance of more explicitly linking student behaviors and effective educational practice. Engagement differs from involvement in that it links more directly to desired educational processes and outcomes and emphasizes action that the institution can take to increase student engagement.

In summary, what are the unique contributions of engagement?

- The concept of engagement is grounded empirically in the indicators of "good practice" in undergraduate education (Chickering \& Gamson, 1987), in involvement theory (Astin, 1984), and in Pace's (1980) quality of effort measures.

- The concept of student engagement is about encouraging institutional reflection and action on effective practice. Specifically, it includes consideration of the institution's role in channeling students' participation in effective educational practice. As a result, it is a concept related to institutional improvement because it immediately pinpoints activities that can be influenced directly and indirectly to improve student learning.

- The NSSE has focused national attention on using student engagement data for the purposes of assessment, accountability and transparency.

\section{Integration}

The term integration is used to explain the extent to which students come to share the attitudes and beliefs of their peers and faculty and the extent to which students adhere to the structural rules and requirements of the institution - the institutional culture (Pascarella \& Terenzini, 1991; Tinto, 1993). The theory of academic and social integration was developed by Tinto (1993) to explain voluntary student departure from undergraduate institutions. Tinto (1993) based his work on VanGennep's (1960) theory of rites of passage in which three phases occur when an individual joins a new group. These phases are: (a) separation from the past, (b) transition, in which the individual begins to interact with new setting and people, and (c) incorporation in which the individual adopts the norms and expectations of the new group. Tinto (1993) also equated departure from college with egotistical suicide as described by Durkheim (1951), which arises when individuals are unable to establish membership within a community. To establish membership in a community, Durkheim (1951) (and Tinto, 1993) argued that individuals need to integrate themselves into the social system. In higher education, integration involves social (personal affiliation) and intellectual (sharing of values) connections.

Tinto's (1993) theory of integration was unique to the field of student development because it was one of the first theories that focused on explaining voluntary departure from colleges and universities as an issue not just with the student but also with the institution. Tinto (1993) argued that prior theories and research had hypothesized and tested financial or academic variables as predictors of student retention and failed to separate voluntary from involuntary departure. $\mathrm{He}$ argued that prior research focused on predictors of dropping out and had a tendency 
to approach the issue in a "blame the victim" sort of way. Tinto's (1993) theory focused on retention and shifted the onus of responsibility from the individual student and his or her personal situation to being an issue under the influence of the institution. The theory is described in the literature as an interactionist theory that looks at both the person and the institution (Tinto, 1986).

Tinto (1993) defined integration with regard to social and academic connection to the campus. Social integration refers to students' perceptions of interactions with the peer group, faculty, and staff at the institution as well as involvement in extra- and co-curricular activities. Academic integration refers to perceptions of the experiences in the formal and informal academic system resulting from interactions with faculty, staff, and students inside and outside the classroom settings that enhance the intellectual development of the student. Tinto (1993) posited that the student's perceived level of integration greatly influences the decision to persist or depart.

Tinto's (1993) model has been used by numerous researchers to test different aspects of integration and to tease out the factors leading to college student departure and retention. There are several instruments used to measure academic and social integration that were developed by researchers looking to apply Tinto's concepts. Tinto's initial work (1986) was mainly theoretical and did not include any particular methodological approach to study the construct of integration. Most research using Tinto's (1993) model of integration measure perceptions of student interactions or connections to faculty and staff and peers along with involvement in extracurricular activities (e.g., Borglum \& Kubala, 2000; Pascarella \& Terenzini, 1980). Pascarella and Terenzini's (1980) scale measures five constructs related to integration and is widely used in the research literature.
The five scales are: Peer Group Interactions, Interaction with Faculty, Faculty Concern for Student Development and Teaching, Academic and Intellectual Development, and Goal and Institutional Commitment.

Some studies have used undergraduate grade point average as a measure of academic integration-but those we interviewed for this project agree that this is problematic as it does not accurately measure what the theory intended. According to Astin, for example:

GPA is a simple measure. We know what it is but it is not a measure of academic integration. ... When people get to practicality it's what people settle with, it is convenient. This over simplifies the construct. This simplistic modeling renders the theory less useful. It reduces it to what can be modeled.

Hurtado agreed that it is especially problematic and all too common for researchers to use grades as a proxy for academic integration. She added, "Grades only capture external validation," they are not a measure of learning or academic connection.

Integration has been subject to critique, given its focus on traditional-age student populations, its lack of attention to racial and ethnic differences, and the prescriptive aspect of the model (e.g., Bean \& Metzner, 1985; Rendon, Jalomo, \& Nora, 2000; Tierney, 2000). For students who are not traditional in terms of race/ethnicity, age, and full-time enrollment status, the assumption is that in order to succeed in college (i.e., to persist) students must become integrated into the college environment by abandoning their history, heritage, and outside interests. Another critique of the theory is that it is too focused on sociological issues and does not take into account the individual psychology of students (Braxton, 2000). Tinto (1993) has responded to these critiques by noting that institutions of higher education are made up of multiple 
communities that attract and serve students from an array of backgrounds. He added that it is important for students to find some form of community membership that helps them to feel connected to the campus, not that they need to assimilate in order to persist.

It is important to note that Chickering (1974) used the term integration in conceptual models of student learning. However, Chickering's (1974) use of the term integration differs from Tinto's (1993). Chickering (1974) proposed that the integration of experiences, namely students' active involvement in a variety of academic and social activities into a meaningful whole, is a critical aspect of student learning. He also indicated that it is the level of student effort, or involvement, that is the most influential factor in integration. As a result, Chickering's (1974) conception of integration has been used to link involvement and engagement to learning gains and to support the causal ordering of engagement, integration, and intellectual development (Pike \& Killian, 2001; Pike \& Kuh, 2005). The fact that the term "integration" has been used by researchers in a way that differs fairly significantly from how the term was used by Tinto (1993) relative to retention and perceptions of institutional fit raises some interesting concerns addressed later in this paper. For the purposes of the present discussion, however, when we use the term integration here we mean it as intended and specified by Tinto (1993) and his research.

In sum, what is the unique contribution of the concepts of academic and social integration?

- Integration is a state of being; it is based on perceptions of student fit with their campus and, by extension, perceptions of interactions reflect the values and norms of the institution and its culture.

- It is focused on specific outcomes. To put it simply, successful integration results in retention and unsuccessful integration contributes to departure.

- Integration is most important for students in their first year at an institution.

- Integration calls for reciprocal commitment of the individual and the institution. That is, the student needs to be willing to become integrated into the college environment and the institution needs to create opportunities for the student to become integrated.

- Integration adopts a cultural view of the campus. Students are departing from past cultural involvement to become integrated into a new culture.

- Integration is about students forming relationships with peers, faculty, and staff and is about the sense of belonging that students develop. It is also a measure of student knowledge of campus cultural norms.

\section{EXAMINING THE OVERLAP BETWEEN THE THREE CONCEPTS}

Based on our analysis, it is quite clear that the terms involvement, engagement, and integration and their application in research and practice have oftentimes been used synonymously and that there is significant overlap and confusion relative to the use of these terms. We believe that this calls for different levels of consideration. First, we consider how the overlap shapes research conversations and then offer consideration for how the overlap influences practice.

\section{Considerations for Research}

Given the conceptual overlap of the constructs, it might not be surprising that the terms are used interchangeably. Astin's (1984) theory of involvement and the concept of student 
engagement reflect the notion that students will invest varying amounts of energy in different activities and that the amount of learning is proportional to the quality and quantity of the college experience. Astin, in fact, believes that there are "no essential differences" between the terms engagement and involvement. He added, "Trying to make a distinction between these two words is probably not all that productive, or necessary." Astin continued, "The NSSE instrument was originally developed under the guidance of a small committee. ... At that time, the committee did not make any significant distinctions between involvement and engagement." Kuh seems to be in partial agreement with this idea that there is a lot of overlap between involvement and engagement. According to Kuh, engagement "was not intended to be a critique or extension of involvement per se." Kuh added that engagement is not a

break-not a sharp turn to the left or right-just another way of thinking about this. ... From a measurement point of view I don't think it makes any difference if you are talking about involvement or engagement and quality of effort. [The concepts of involvement and engagement] are temporal representations of pretty much the same thing-especially if you narrow the focus of engagement and quality of effort on a variety of things that all have empirical links to student development.

The unique contribution of engagement rests in the origin of the NSSE project: to introduce a new approach to gathering information about collegiate quality, to inform institutional improvement efforts and understand dimensions of college quality on a national basis, and to increase opportunities to compare results among peer institutions and identify best practices.

Pascarella suggested that his latest book of the impact of college on students (Pascarella \&
Terenzini, 2005) did not attempt to distinguish the two terms and that they are used somewhat interchangeably throughout the text. Sax concurred that it is common for people to mistakenly use the terms synonymously. Tinto also believes that "it is hard to see how [involvement and engagement] differ. They are used together."

So, why have a different word if they are essentially the same? In response, Kuh offered an explanation:

Every generation needs its own way to understand the world-this kind of progression, this shifting of labels, represents more than just a temporal adjustment. The larger construct of engagement puts more responsibility on the institution-which is an important tweak... You have to shape the shoe to fit the foot or provide sandals and find ways people can slide a foot into the institution without having their toes cramp.

Kuh continued,

Involvement doesn't have the link to desired outcomes nor does it have the focus on the institution. It is what the student does. Involvement is not sufficient for advancing institutional efforts-you need to know what the institution is doing as well.

Stage's response was similar:

The terms change slightly when an author wants to provide a new point of view. The terms get adapted based on the point the author is trying to make. For example, when Don Hossler and I worked on our model for John Braxton's book on student departure [Stage \& Hossler 2000], we were interested in describing the student as an active agent as opposed to a "recipient" of institutional efforts to integrate him or her. So in our model we used the term involvement and we described exactly why we were not using the term integration. 
Braxton also viewed the terms as being different. He stated, "Engagement is more powerful than involvement." Further, Harper added that there is a "key qualitative difference [between involvement and engagement] as it is entirely possible to be involved but not engaged." Harper elaborated on this distinction, noting that students can "show up and could legitimately claim that they are involved but they are not really engaged. . . . Engagement is amount plus depth, which leads to favorable outcomes."

Certainly the instruments primarily used to measure the concepts of engagement and involvement differ from one another. The CIRP includes several survey instruments including one for entering freshmen, Your First College Year Survey, the College Senior Survey, and the HERI faculty survey. These instruments provide a longitudinal data base through which researchers can explore the relationships between input variables, college environment, involvement, and college outcomes. The CIRP is the oldest and largest empirical study of higher education and involves over " 1,800 institutions and over 11 million students" (CIRP, 2008). Questions on the CIRP surveys ask about student values and their experiences in and before college. The questions deal with extracurricular and academic experiences. The NSSE survey was first administered in 2000 and has had over 1,200 institutions participate. The surveys are administered to a random sample of firstyear students and to seniors at participating institutions in the spring term. NSSE results are most commonly used as panel data but are also increasingly being used in longitudinal designs and with student characteristics added as input controls. The NSSE survey tends to be more narrowly focused on those activities that have been directly linked to positive educational outcomes (as per Chickering and Gamson, 1987, for example) as compared to
CIRP. According to Astin, "CIRP opts for greater breadth."

Based on a review of the literature and interviews with those who developed and apply the theories of involvement and engagement it is clear that the distinction between these two concepts is not clearly delineated. It is not surprising that researchers conflate these terms. The finding we highlight here about these two concepts is that, although there is considerable overlap, there is still distinction and it is important for researchers, in particular, to present the nuances of the terms they use. The origins of the concepts clearly build on one another and are probably the basis for the overlap. An important part of the research process is clarification of terms and development of ideas that one uses in research. To develop a sound body of research related to student development it is important to be clear about the use of terms.

The experts we interviewed clearly saw integration as a theory separate and distinct from engagement and involvement. Tinto's (1993) integration theory is more sociological than involvement and engagement, given its focus on sharing normative values. Astin commented on this idea, agreeing that "integration is more social in its connotation . . . it's sort of like, to what extent are you bought into the ethos of the institution?" However, he mused on the paradox of difference and the application of the three terms by describing that a student participating in a marginalized group might feel alienated at the institution but be very involved and engaged with this organization.

Sax suggested that "integration is a byproduct of or a positive form of involvement. ... It is not any particular behavior, but more a sense of being a part of the campus community." Stage described integration as an antecedent to involvement and engagement. First, students gain comfort and a sense of fit with the institution and then they are willing 
to get involved and engaged. In contrast, Kuh suggested that "you become integrated through involvement and engagement, by devoting effort to things that promote positive outcomes." He added, "You don't get integrated academically or socially unless you do something. Integration is an outcome." Kuh's conception of the term integration seems to align more closely to Chickering's (1974), in that integration is the critical act of connecting one's active involvement in educationally purposeful academic and social experiences and understanding how ideas and experiences come together to make a meaningful whole.

Tinto's perception of the relationship between the three concepts is more distinct. $\mathrm{He}$ described involvement and engagement as behaviors and integration as a "state or a perception of fit." Braskamp affirmed this characterization. Tinto elaborated further by explaining that neither involvement nor engagement measure perceptions of fit.

The term integration has an idea of learning the rules of the game (the culture)—engagement and involvement have no such component. ... It is true that being engaged is better than not being engaged at all. But, being engaged does not mean that you feel included and valued as a member of the community.

Braxton indicated that researchers often use the wrong term in their research when it comes to these three concepts. He explained that sometimes social integration is equated with joining a fraternity, for example. $\mathrm{He}$ added, "That's involvement. ... That is the classic example of how [integration] is used incorrectly." Tinto further explained that a large part of the problem with the idea of integration has to do with measurement concerns. He elaborated:

The problem is we try to use one-dimensional measures to capture multidimensional phenomenon. We need a word, a measure and we want it to be simple. Unfortunately, it takes more than a simple term to capture the full complexity of the theory.

Harper added,

In studies, researchers don't always make distinctions between the concepts and when they are measuring student behavior they tend to focus on the amount of involvement so they catalog student experiences as opposed to studying the depth of those experiences.

An important distinction between the three concepts is the origins of the work. Tinto's (1993) work was initially theoretical and was developed to advance thinking related to student departure and persistence. Other researchers built upon Tinto's work to develop instruments to measure different aspects of integration. In contrast, Astin's (1984) development of the concept of involvement was directly linked to CIRP findings. Engagement was a concept that was developed, in part, based on empirical research on best practices related to undergraduate education. The NSSE was developed specifically to gather information about collegiate quality, with items derived from CSEQ and CIRP. The impetus for the development of the ideas is one way the concepts are distinct and unique.

One area of overlap is that all these concepts face methodological challenges. All three concepts-involvement, engagement, and integration-must respond to the challenge of predisposition. Astin explained,

Students come to college with varying predispositions to become involved, become engaged, or become integrated. It is for this reason that CIRP emphasizes the longitudinal nature of the problem and the need to collect 'input' data in order to control for the biasing effect of these predispositions. 
Further, he explained, "To sort out the selfselection aspect from positive experience is a tough methodological challenge." Astin (1984) developed the I-E-O model to respond to the challenge of self-selection. Sorting out the bias of self-selection is a hurdle that all college outcome research must respond to.

Another methodological area of overlap has to do with idea development and attribution. The interview findings from Astin, Kuh, and Tinto, in particular, point to the common issue that as researchers they developed the initial ideas related to involvement, engagement, and integration and it is other researchers who apply the concepts, sometimes in ways that are not intended. For example, a cited limitation of Astin's involvement theory is that it is limited to traditional age college students. Although, Astin's (1984, 1993, 1999) work is often used to explain the traditional age college student, Astin himself never limited his work to traditional age students. Tinto also indicated that some of his ideas had been developed in ways that were never intended. Student development research is constantly being expanded and the initial ideas put forth by Kuh (1991), Tinto (1993), and Astin (1984) are used and developed in ways beyond the researchers' original intentions. In part, the purpose of this paper is to encourage researchers to be clear about the origin and development of ideas.

Thinking about the I-E-O model in relationship to studies about the concepts of involvement, engagement, and integration brings up another interesting concern for researchers. Specifically, in examining the literature it is not always clear whether researchers are viewing these concepts as measures of input, environment, or as outcomes. Although it appears that these concepts were initially intended to be measured as environmental variables (what students experience once on campus) there are many studies that use these concepts as outcome measures. This happens, for example, when researchers are studying retention and do not have access to students who are no longer retained. In such cases, they use involvement, engagement, or integration as an outcome variable. Sax and Hurtado, in particular, noted that too often involvement, engagement, and integration are mistakenly referred to as outcome variables rather than as environmental variables. Hurtado explained, "Involvement and engagement are the means not the ends ... ends should be civic responsibility, retention, and the essential goals of higher education." Interestingly, in an article about assessment and accountability, Shulman (2007) argued that NSSE items can serve as good "proxies for outcomes." He continued that "the instrument itself measures the kinds of experiences students have over the course of their academic careers."

Harper pointed out that the three concepts are actually being used as "input" measures rather than measures of the environment because the focus is on the perceptions and behaviors of the student. Harper explained, "We tend to think of these things as what students do and what students bring to the table rather than what the institution does. In measuring the concepts they essentially become inputs rather than measures of the environment." The fact that these concepts can be used as measures representing inputs, environments, or outputs is not necessarily problematic; however, it does add to the confusion surrounding the use of these terms in research and points to the need for researchers to explain their use of terms and concepts.

\section{Considerations for Practice}

The concepts of involvement, engagement, and integration provide practitioners with a framework for understanding and fostering 
student learning and success and also offer cues for developing rich contexts for student learning and development. For these purposes, the precision of terms in the development of practice may have less consequence than in scholarly research. As Stage concluded, "We should not scold practitioners for using integrate or involve [interchangeably].... Research should be defined pretty clearly, but we should think more boldly about what the terms offer in our theorizing and see many options for using them."

From a practical application standpoint, the NSSE is less concerned about a lack of precision in its measures. Kuh explained, "I am not as concerned with [precision of definition] as I am with trying to leverage institutional change towards focusing more on the things that matter and we can change and less on the things we can't influence." The student engagement construct and the survey results are designed with practical aims.

NSSE is not primarily a research project. NSSE is primarily a national initiative to change the way people talk and think and act about what matters to collegiate quality and student learning. So, there are things about NSSE that aren't perfect in terms of its measures - if we were doing it again or we weren't worried about people using it over time we would change things now. We would add or subtract thingsbut when you are in year eight people don't want you to change things,

said Kuh. As a result, the value of NSSE should be determined by the extent to which it can inform and foster improvement in undergraduate education.

Through administering surveys such as the CIRP student surveys and the NSSE, practitioners concerned about student success can gain instructive insights about their students' educational experiences and what they value in terms of educational activities. For example, through survey results, faculty members can become more aware of entering students pre-college experiences and expectations for collaborating with classmates in college and the extent to which first-year students are receiving timely and apt feedback about their performance and are talking with faculty about grades and assignments and ideas outside of class. This information can be used to shape expectations for collaboration among students and to create assignments that require collaborative learning and campus cultures in which faculty are accessible and responsive to all students (Goodsell, Maher, \& Tinto, 1992; Kuh et al., 2005)

These three concepts have all achieved relevance for practice. They emerged out of a concern to develop a greater understanding of students and their experiences in higher education and have added to practitioners' ability to respond well to students and to create effective learning environments. That said, there is room to be critical of the overemphasis these concepts place on the student as the agent and their underestimation of the role of institutional agents in fostering involvement, engagement, and integration. Bensimon's (2007) critique of research related to involvement, engagement, and integration (and related student development research) is that it is the practitioner-student relationship that most matters to students and this tends to be overlooked in a majority of the research using the constructs. Overemphasis on the student and the activities in which he or she is involved or engaged (or not) and if he or she is integrated (or not) places too much emphasis on student attributes or deficits and not enough on practitioners and practices that promote student development and learning. Harper agreed with this critique, arguing that because most of the research surrounding these concepts collects data from students one can sometimes fail to hold institutions 
accountable for their role in the equation. To combat this concern, Harper recommended that researchers studying the effect of college on students ought to focus as much on the behaviors and perceptions of faculty and administrators as they do on students.

\section{CURRENT CONCERNS AND IMPLICATIONS FOR THE FUTURE}

Involvement, engagement, and integration are terms that are used frequently and often interchangeably in research and practice related to student learning and development. These constructs have achieved the status of common knowledge; they are in some respects paradigmatic. Bensimon (2007) raised pointed questions about overreliance on the "dominant paradigm," a phrase she used as an umbrella term for current epistemology motivating quantitative studies of student success that include variables such as student background characteristics; structural characteristics of institutions; and interactions with faculty, staff members, and peers. She concluded that scholars of higher education should honor the role that practitioners play in developing more inclusive theories of student success.

If our goal is to do scholarship that makes a difference in the lives of students whom higher education has been least successful in educating (e.g., racially marginalized groups and the poor), we have to expand the scholarship on student success and take into account the influence of practitioners- positively and negatively. (p. 445)

This critique is important because it advocates that theories about student success expand beyond a focus on attributing success to individual effort and incorporate greater emphasis on the characteristics of practitioners.

Stage suggested a more general caution about the use of prevailing models, including the concern that models permit organizational and research complacency. The use of particular theories in research "can become status quo because we have a model. Researchers plug in the data, run the regression, and get the results. Voila, theory confirmed again!" Stage asserted:

If you want to do something to change the status quo then we really have to upend the models - we have to change the questions. Who do we want to see participate in higher education? What then can we say about their persistence? This would not be a critique of engagement, involvement, or integration models, but if we want to understand all students and their experience for example, we need to be careful about replicating the models.

An important concern about these concepts is the extent to which they fail to represent the experiences of students historically underrepresented in higher education. This critique has prompted challenges to all three concepts. Specifically, a critique of involvement and engagement is that they are more applicable constructs for full-time, traditional age, and residential students (Bean \& Metzner, 1985). Kuh responded to this critique:

We have the adult learner folks saying these terms are "dormocentric." This is all about traditional aged students living on campus. I say, let's read through these itemswhich of these items are "dormocentric." [Nontraditional age students] don't participate in extracurricular activities. There are a lot of traditional aged students who don't participate in those either. What is the problem?

Although Kuh, as the chief architect for the study of engagement, is open to critique, the concerns do not always get reflected in what critics see as "dormocentric" research. More importantly, student engagement has been found to have almost uniformly positive effects 
for all students, including adult and distance education learners (NSSE, 2006), and salutary effects for lower ability students as well as students from different racial/ethnic groups (Kuh, Kinzie, Cruce, Shoup, \& Gonyea, 2006).

In spite of attempts to be inclusive, the concepts of involvement, engagement, and integration have been built and tested based on assumptions that largely fit criteria associated with full time, traditional age, and residential students. It follows suit then that findings from these theories will gravitate toward measures of central tendency and as a result not be as descriptive and explanatory for students on the margin (Bensimon, 2007; Harper \& Quaye, 2008). Researchers need to be aware not only of the definition of the terms involvement, engagement, and integration but also of the underlying epistemological and methodological assumptions that guide the study and use of the terms.

Harper, Hurtado, and Sax stressed that it is the quality of the interaction that matters more than just engaging in the activity itself. Such a distinction calls for more nuanced ways of measuring the constructs and more qualitative assessments. Sax offered an example of the need to consider the nature and quality of student interactions with faculty:

[Students] could visit faculty during office hours [an indicator of engagement] and for some students that will lead to [further] engagement and would be a positive outcome. But for others that go and ask a couple of questions, maybe they feel dismissed or "blown off" and they don't feel more engaged.

Sax also suggested that it is important to consider the conditional effects of involvement and engagement. She asked, "Is the effect [of involvement and engagement] different for one group than another? Are some forms or types of engagement and involvement more effective for some types of students than for others?" In a recently published article, Hurtado (2007) noted that what is missing from research on these concepts is some measure of the "opportunity structure" and how that varies campus by campus and for different groups of students. These structures can sometimes be captured by measuring characteristics of the institution, like size, resources, selectivity, and even racial composition of the campus. However, although these variables should be measured, there are also larger social forces that are more difficult to capture. These are the issues that remain unanswered and deserve more attention in research and practice.

Tierney (2000), Rendon et al. (2000), Hurtado (2007), and Harper and Quaye (2008) have critiqued Tinto's (1993) model of integration for its failure to account for the implication that integration into predominantly White environments might have adverse consequences and be difficult to accomplish for students from racially and ethnically diverse groups. According to Hurtado (2007), Tinto's (1993) model calls for "normative congruence," which implies that acculturation of historically marginalized groups and "conformity to dominant modes of thinking and acting that is least likely to be adopted by nontraditional students" (p. 4). Tinto (1993), in his revision of his theory, countered that conformity is not necessary for integration and that, in fact, students from historically marginalized groups might integrate into the campus by finding membership in subgroups on campus. Ironically, we learned from our interview that Tinto agrees with this critique of integration as commonly used.

The future of integration as a theory-or at least as a term to be used by researchers and practitioners - was questioned by Tinto himself. "I don't use the word integration anymore-haven't used it in decades." It is not that Tinto does not believe that his 
theory is predictive of student retention; rather he believes that the term "integration" is problematic, as has been pointed out by Tierney, Hurtado, and others (see Hurtado, 2007; Tierney, 2000). Part of understanding the current problem with the term integration has to do with its historical context. According to Tinto, when he and Spady used the term integration, initially they meant it to stand in opposition to segregation. The term was

meant to be the opposite of exclusion or segregation. ... We never meant that students had to become congruent with or assimilate to the White culture. ... We weren't using this to say Blacks had to become White-we were talking about the term in the context of the conversations of the 1960s that integration was the opposite of segregation-you had to be included in society.

Today, however, the term is problematic because it has been interpreted to mean "you have to make them become like us." Tinto added that Tierney's (2000) critique of the word is correct because it calls upon students of color to give up their own cultural heritage in order to survive in predominantly White colleges and universities. Indeed Tinto concluded: "In the current context, the word doesn't make sense. It needs to be gotten rid of." At the same time, Tinto suggested that his theory, as written, is still accurate as a predictor of retention and that part of the problem is that people are trying to simplify the measure and not look at the theory in its complexity.

What, then, should substitute for the term integration? Tinto suggested that one way to think about the notion of integration is to think about it in terms of role theory. He explained, "Role theory suggests that to be successful, people have to develop a series of roles that they have to learn how to play." He provided the following example:
Hispanic students have to know how to play by the rules of the institution, what values exist and how to negotiate that world. It doesn't mean they have to become White-but they have to be conversant with the rules of the game. There is some sense of having to play the role. ... It isn't you; it's the role you play. That is the difficult part for students of color-how to conserve a sense of who you are while you are playing this other role.

"Role theory, or "code switching" (Harper \& Quaye, 2008), has been identified as a mechanism that underrepresented students employ to negotiate and find a place within the campus environment. Tinto added that Hurtado's (2007 work on students of color influenced his current thinking about integration. She had pointed out that students' perceptions are of key importance-what drives retention are the meanings people make from their interactions with people on campus. Tinto suggested that "sense of belonging" may be a good substitute for a term like integration. He added, however, that

it isn't just your connection to other people-it is how you see your connections on campus vis-à-vis other groups. Students need to feel connected in ways that do not marginalize or ghettoize. . . They need to feel welcomed not threatened.

As an analogy, Tinto suggested that it might be helpful to think about connections on campus as being akin to the solar system.

Though it is important to see oneself as $s$ member of a group or smaller community of people, it is also important that one sees that group or community as being included in the mainstream, as opposed to in the margins, of campus life. Like planets that sit at the outer reaches of a solar system, the pull of gravity to the center is weak and the impact of the sun greatly attenuated. Even the slightest 
external force can pull the planet away from the system.

Hurtado also suggested that "sense of belonging" or "social cohesion" is an important element of where the idea of Tinto's integration ought to be heading. That said, Harper noted that we need more research on the extent to which the idea of "sense of belonging" is related to positive educational outcomes such as retention.

The concepts of involvement, engagement, and integration have demonstrated their staying power in higher education scholarship and practice. Stage asserted the value of these models, but questioned the tradition of continually testing the theory.

As long as the models are useful then they'll stick around, but we need to let go of them when they are not. Tinto's model did get people to think more about retention and that we ought to be concerned about why students leave. Now it goes without saying that practitioners and researchers need to know the theory, but it does not mean we have to keep testing the theory.

Although it is clearly important to remind the research community of the theory, and for young researchers to test it and know it for themselves in terms of replication in scholarship, it is perhaps more important for institutions to discover or understand differences among groups of students and how involvement, engagement, and integration occurs or does not occur for these students.

\section{CONCLUDING THOUGHTS ON INVOLVEMENT, ENGAGEMENT AND INTEGRATION}

The overwhelming weight of evidence indicates that involvement, engagement, and integration are useful theories for research and practice. The concepts have remarkable salience among scholars and practitioners. Of course, there is still room to improve understanding of the constructs and operationalizing them in research and practice. Astin suggested:

Involvement or engagement are very generic constructs. We have not done enough work on the varieties of engagement and what kinds of involvement are positive, or related. For example, political involvement is negatively involved with retention, and satisfaction, it's not a uniformly positive experience. Look at exceptions and think about why some forms of involvement are negatively related to development.

The ongoing development of theory calls for the continual revision of theory based on new learning. The ongoing rigor of research using any theory calls for understanding the development, application, and nuances of theory building and use.

Based on our analysis, it may be helpful to visualize the three concepts. Involvement is the responsibility of the individual student, though the environment plays a role. The unit of analysis for involvement is the student and his or her energy; it is the student who becomes involved. Integration (or what Tinto might now call "sense of belonging") involves a reciprocal relationship between the student and the campus. To become integrated, to feel like you belong, a student must learn and adopt the norms of the campus culture, but the institution is also transformed by that merger. The focus on engagement is on creating campus environments that are ripe with opportunities for students to be engaged. In most of the recent engagement research, the institution, not the student, is the unit of analysis. Although the construct of engagement accounts for individual student behaviors (i.e., what the student is engaged in) and research on student engagement is typically conducted from the student perspective, NSSE results are aggregated to the institution level to encourage 
institutional research and examination of institutional practice and effectiveness. The reason for the confusion about these concepts is that all three focus on student development and success, each concept contributing a unique and nuanced piece of understanding to the puzzle.

What we have learned from the process of writing this article is that theory building is an ongoing conversation. Some of these conversations take place in the formal literature and some of these conversations do not. We have also learned that the problem with concepts achieving paradigmatic levels is that they come to be used in ways that are beyond what was intended. Left unattended, researchers and practitioners can easily lose sight of the original intent of a particular concept. Given the prevalence of use in theory and practice of the terms involvement, engagement, and integration, it is particularly important to tease out the nuances of these concepts in research related to student development and success. The scholarly process itself, like writing this paper, is an opportunity to stop, take stock, and proceed cautiously with use of theory in research and practice. Increased attention from the federal government and education policy makers regarding concerns about the quality of undergraduate education has brought increasing attention from a wider audience about the impact of college and what is needed to increase student success. Common definitions, clear terminology, and openness to critique of dominant paradigms will help researchers, practitioners, and others address growing concerns in higher education.

Correspondence concerning this article should be sent to Lisa Wolf-Wendel, 1122 W. Campus Rd., Joseph R. Pearson Hall, Room 419, University of Kansas, Lawrence, KS 66045-3101; lwolf@ku.edu 


\section{REFERENCES}

Astin, A. W. (1975). Preventing students from dropping out. San Francisco: Jossey-Bass.

Astin, A. W. (1977). Four critical years. San Francisco: JosseyBass.

Astin, A. W. (1984). Student involvement: A developmental theory for higher education. Journal of College Student Personnel, 25, 297-307.

Astin, A. W. (1985). Achieving educational excellence: A critical assessment of priorities and practices in higher education. San Francisco: Jossey Bass.

Astin, A. W. (1993). What matters in college? Four critical years revisited. San Francisco: Jossey-Bass.

Astin, A. W. (1999). Involvement in learning revisited: Lessons we have learned. Journal of College Student Development, 37(2), 123-133. Retrieved May 9, 2008, from http://findarticles.com/p/articles/mi_qa3752/is_/ ai_n8856623?tag = artBody;col1

Batteson, C., \& Ball, S. J. (1995). Autobiographies and interviews as means of "access" to elite policy making in education. British Journal of Educational Studies, 43(2), 201-216.

Beamer, G. (2002). The practical researcher: Elite interviews in state political research. Politics, 2, 86-97.

Bean, J., \& Metzner, B. (1985). A conceptual model of nontraditional student attrition. Review of Educational Research, 55, 485-540.

Bensimon, E. M. (2007). The underestimated significance of practitioner knowledge in the scholarship on student success. Review of Higher Education, 30(4), 441-469.

Borglum, K., \& Kubala, T. (2000). Academic and social integration of community college students: A case study. Community College Journal of Research and Practice, 24, 567-576.

Braxton, J. M. (2000). Reworking the student departure puzzle. Nashville: Vanderbilt University Press.

Bruffee, K. A. (1993). Collaborative learning: Higher education, interdependence, and the authority of knowledge. Baltimore: Johns Hopkins University Press.

Chickering, A. (1974). Commuting versus residential students: Overcoming educational inequities of living off campus. San Francisco: Jossey-Bass.

Chickering, A. W., \& Gamson, Z. F. (1987). Seven principles for good practice in undergraduate education. AAHE Bulletin, 39(7), 3-7.

Chickering, A. W., \& Reisser, L. (1993). Education and identity (2nd ed.). San Francisco: Jossey-Bass.

Denzin, N. (1978). The research act: A theoretical introduction. New York: McGraw Hill.

Dexter, L. A. (1970). Elite and specialized interviews. Evanston, IL: Northwestern University Press.

Durkheim, E. (1951). Suicide: A study in sociology. New York: The Free Press of Glenco.

Goodsell, A., Maher, M., \& Tinto, V. (Eds.). (1992). Collaborative learning: A sourcebook for higher education. University Park: National Center on Postsecondary Teaching, Learning and Assessment, Pennsylvania State University.
Harper, S. R., \& Quaye, S. J. (2008). Student engagement in higher education: Theoretical perspectives and practical approaches for diverse populations. London: Routledge.

Hernandez, K., Hogan, S., Hathaway, C., \& Lovell, C. (1999). Analysis of the literature on the impact of student involvement on student development and learning: More questions than answers? NASPA Journal, 36(3), 1-15.

Hurtado, S. (2007). The sociology of the study of college impact. In P. Gumport's (Ed.), The sociology of higher education: Contributions and their contexts (pp. 94-112). Baltimore: Johns Hopkins University Press.

Kuh, G. D. (2001). Assessing what really matters to student learning: Inside the National Survey of Student Engagement. Change, 33(3), 10-17, 66.

Kuh, G. D., Kinzie, J., Buckley, J., Bridges, B., \& Hayek, J. C. (2007). Piecing together the student success puzzle: Research, propositions, and recommendations. ASHE Higher Education Report, 32(5). San Francisco: Jossey-Bass.

Kuh, G. D., Kinzie, J., Cruce, T., Shoup, R., \& Gonyea, R. M. (2006). Connecting the dots: Multifaceted analyses of the relationships between student engagement results from the NSSE and the institutional policies and conditions that foster student success. Final report to Lumina Foundation for Education. Bloomington: Indiana University Center for Postsecondary Research.

Kuh, G. D., Kinzie, J., Schuh, J., Whitt, E., \& Associates. (2005). Student success in college: Creating conditions that matter. San Francisco: Jossey-Bass.

Kuh, G. D., Schuh, J. S., Whitt, E. J., \& Associates. (1991). Involving colleges: Successful approaches to fostering student learning and personal development outside the classroom. San Francisco: Jossey Bass.

Kvale, S., \& Brinkmann, S. (2009). Interviews: Learning the craft of qualitative research interviewing ( $2 \mathrm{nd}$ ed.). Thousand Oaks, CA: Sage.

McKeachie, W. J., Pintrich, P. R., Lin, Y. G., \& Smith, D. (1986). Teaching and learning in the college classroom: A review of the research literature. Ann Arbor: National Center for Research to Improve Postsecondary Teaching and Learning, University of Michigan.

McPherson, P., \& Shulenburger, D. (2006, August). Toward a public universities and colleges voluntary system of accountability for undergraduate education (VSA): A NASULGC and AASCU discussion draft. Washington, DC: NASULGC. Retrieved November 1, 2008, from http://www.nasulgc.org/vsa8-3106\%20_7_\%20_2_.pdf

National Center for Education Statistics. (n.d.). Research \& Development: National Postsecondary Education Cooperative (NPEC). Retrieved November 1, 2008, from the U.S. Department of Education, Institute of Education Sciences web site: http://nces.ed.gov/npec/symposium.asp

National Center for Higher Education Management Systems. (1994). A preliminary study of the feasibility and utility for national policy of instructional "good practice" indicators in undergraduate education. Boulder, CO: Author.

National Institute of Education. (1984). Involvement in learning: Realizing the potential of American higher education. Washington DC: Author. 
National Survey of Student Engagement. (2000). The NSSE 2000 report: National benchmarks of effective educational practice. Bloomington, IN: Indiana University Center for Postsecondary Research and Planning.

National Survey of Student Engagement. (2006). Engaged learning: Fostering success for all students. Bloomington, IN: Indiana University Center for Postsecondary Research.

National Survey of Student Engagement. (2008). Web data downloaded May 9, 2008: http://nsse.iub.edu/html/origins.cfm

Pace, C. R. (1980). Measuring the quality of student effort. Current Issues in Higher Education, 2, 10-16.

Pace, C. R. (1984). Measuring the quality of college student experiences. Los Angeles: University of California, Center for the Study of Evaluation.

Pascarella, E. T., \& Terenzini, P. T. (1980). Predicting freshman persistence and voluntary dropout decisions from a theoretical model. Journal of Higher Education, 51(1), 60-75.

Pascarella, E. T., \& Terenzini, P. T. (1991). How college affects students: Findings and insights from twenty years of research. San Francisco: Jossey-Bass.

Pascarella, E. T., \& Terenzini, P. T. (2005). How college affects students: A third decade of research. San Francisco: JosseyBass.

Pike, G. R. (1993). The relationship between perceived learning and satisfaction with college: An alternative view. Research in Higher Education, 34, 2340.

Pike, G., \& Killian, T. (2001). Reported gains in student learning: Do academic disciplines make a difference? Research in Higher Education, 42(4), 429-454.

Pike, G. R., \& Kuh, G. D. (2005). First-and second-generation college students: A comparison of their engagement and intellectual development. Journal of Higher Education, 76(3), 276-300.
Rendon, L., Jalomo, R., \& Nora, A. (2000). Theoretical considerations in the study of minority student retention in higher education. In J. M. Braxton (Ed.), Reworking the student departure puzzle. Nashville: Vanderbilt University Press.

Shulman, L. (2007). Counting and recounting: Assessment and the quest for accountability. Change. Downloaded May 5, 2008, from http://www.carnegiefoundation.org/change/sub. asp?key $=97 \&$ subkey $=2169$

Stage, F. K., \& Hossler, G. (2000). Where is the student? Linking student behaviors, college choice and college persistence. In J. Braxton (ed.) Rethinking the departure puzzle: New theory and research on college student retention. Nashville: Vanderbilt University Press.

State Higher Education Executive Officers. (2005). Accountability for better results: A national imperative for higher education. Boulder, CO: Author.

Tierney, W. G. (2000). Power, identity and the dilemma of college student departure. In J. M. Braxton (Ed.), Reworking the student departure puzzle. Nashville: Vanderbilt University Press.

Tinto, V. (1986). Theories of student departure revisited. In J. Smart (Ed.), Higher education: Handbook of theory and research. New York: Agathon Press.

Tinto, V. (1993). Leaving college: Rethinking the causes and cures of student attrition (2nd ed.). Chicago: University of Chicago Press.

U.S. Department of Education (2006). A test of leadership: Charting the future of U.S. higher education. Washington, DC: Author.

VanGennep, A. (1960). The rites of passage. London: Routledge. 